\title{
Balloon pulmonary angioplasty in a patient with chronic thromboembolic pulmonary hypertension
}

\author{
To the Editor:
}

We report the first French case of percutaneous balloon pulmonary angioplasty (BPA) in a 78-year-old patient with chronic thromboembolic pulmonary hypertension (CTEPH). The patient had a history of acute pulmonary embolism in 2004 with recurrence in 2011. At the end of 2012, he complained of persistent dyspnoea and CTEPH was diagnosed on lung radionuclide perfusion scan, contrast chest computed tomography and right heart catheterisation. At the first evaluation, he was in New York Heart Association (NYHA) functional class III and his 6-min walk distance (6MWD) was $470 \mathrm{~m}$. Mean pulmonary artery pressure (mPAP) was $45 \mathrm{mmHg}$, cardiac index $1.8 \mathrm{~L} \cdot \mathrm{min}^{-1} \cdot \mathrm{m}^{-2}$ and pulmonary vascular resistance (PVR) 8 Wood units. He had used warfarin for 2 years, and combination therapy with bosentan and tadalafil was started (1 year before angioplasty) [1,2]. Conventional pulmonary angiography showed that the main lesions were located in segmental pulmonary arteries of the lower lobes (fig. 1c). Webs, splits and occlusion were identified in A6, A8, A9 and A10 pulmonary arterial branches on the right lung, and A8, A9 and A10 on the left lung (fig. 1a).

Pulmonary endarterectomy (PEA) was considered as feasible but at high risk given the age and the haemodynamic status of the patient $[3,4]$. In addition, the patient declined surgical treatment. Therefore, percutaneous BPA was proposed for the treatment of this CTEPH as it has been promoted by Japanese groups [5, 6] and recently by a Norwegian group [7]. Renal function was normal. This protocol was approved by our institutional review board and ethics committee (Comite de Protection des Personnes SudEst V, Grenoble, France). The patient gave informed consent. He was hospitalised the day before the procedure. We maintained warfarin to achieve an international normalised ratio (INR) of 2.0. The procedure was conducted under local anaesthesia, through the right femoral vein. A $6 \mathrm{~F}$ guide catheter (Judkins Right Launcher; Medtronic, Minneapolis, MN, USA) was used for each procedure (right pulmonary artery first and left pulmonary artery 8 days after). A 0.014 hydrophilic wire (Pilot 50; Abbott Vascular, Santa Clara, CA, USA) was inserted through target lesions (fig. 1c). We injected $50 \mathrm{U} \cdot \mathrm{kg}^{-1}$ of unfractionated heparin intravenously at the beginning of the procedure. Then, heparin was given at a dose of $1000 \mathrm{U}$ every hour until the end of the procedure.

BPA was performed with a $2 \times 20$-mm coronary balloon inflated in each target lesion, followed by coronary or renal balloons that were sized to be $80 \%$ of the vessel diameter (fig. 1b), as measured by optical coherence tomography (OCT) (fig. 1d). BPA of three segmental branches of the right lower lobe was conducted. Additional BPA of three segmental branches of the left lower lobe was performed 1 week later. The objective for each target vessel was to obtain an angiographic pulmonary flow grade 3 (fig. 1e) [8]. Each procedure required $350 \mathrm{~mL}$ of contrast agents. The cumulative radiation dose was $282 \mathrm{~Gy} \cdot \mathrm{cm}^{-2}$. At the end of the second procedure, mPAP was $29 \mathrm{mmHg}$, cardiac index was $2.5 \mathrm{~L} \cdot \mathrm{min}^{-1} \cdot \mathrm{m}^{-2}$ and PVR was 4 Wood units.

The patient developed moderate haemoptysis due to reperfusion pulmonary injury $1 \mathrm{~h}$ after each procedure, which resolved spontaneously. No sign of arterial rupture or wire injury was visualised on the final angiographic assessment. Vasa vasorum rupture or alveolar flooding reperfusion may arise. This complication seems to be frequent, up to $50 \%$ in recent published series. The patient was hospitalised in the intensive care unit for $48 \mathrm{~h}$ and was discharged from the hospital on the fifth day after each procedure. Maintenance of warfarin, to bring the INR to 2, was our choice to limit haemorrhagic and thrombotic risk around angioplasty, and avoid post-procedure discharge delay; working under heparin could be a safeguard against bleeding during angioplasty.

The specific pulmonary hypertension therapy was also maintained. 3 months after the last procedure, his functional status was improved (NYHA functional class II), 6MWD was stable at $478 \mathrm{~m}$, mPAP was $35 \mathrm{mmHg}$, cardiac index $2.5 \mathrm{~L} \cdot \mathrm{min}^{-1} \cdot \mathrm{m}^{-2}$ and PVR 4 Wood units.

Balloon pulmonary angioplasty seems to be a feasible and efficient technique for the treatment of CTEPH in patients with operable form but unacceptable risk for PEA. With OCT monitoring, BPA for CTEPH lesions seems to be safer [6]. The technique needs to be standardised to avoid haemorrhagic, renal and radiation risks, and to ensure reproducibility. 
a)

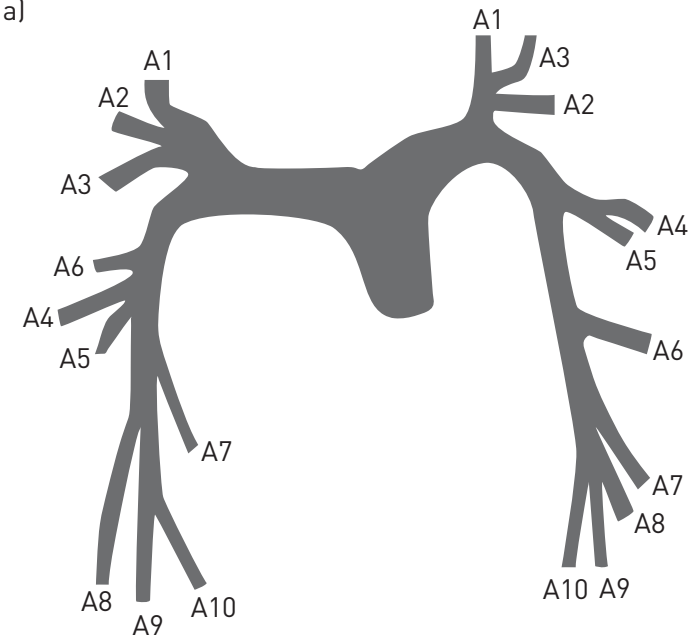

b)

\section{Segment Balloon size $\mathrm{mm}$ Pressure atm}

\begin{tabular}{ccc}
$\begin{array}{c}\text { Right lung } \\
\text { A6 }\end{array}$ & 4 & 4 \\
A8 & 4 & 4 \\
A9 & 6 & 6 \\
A10 & 8 & 8 \\
Left lung & & \\
A8 & 6 & 6 \\
A9 & 4 & 8 \\
A10 & 6 & 8 \\
\hline
\end{tabular}

Right lung
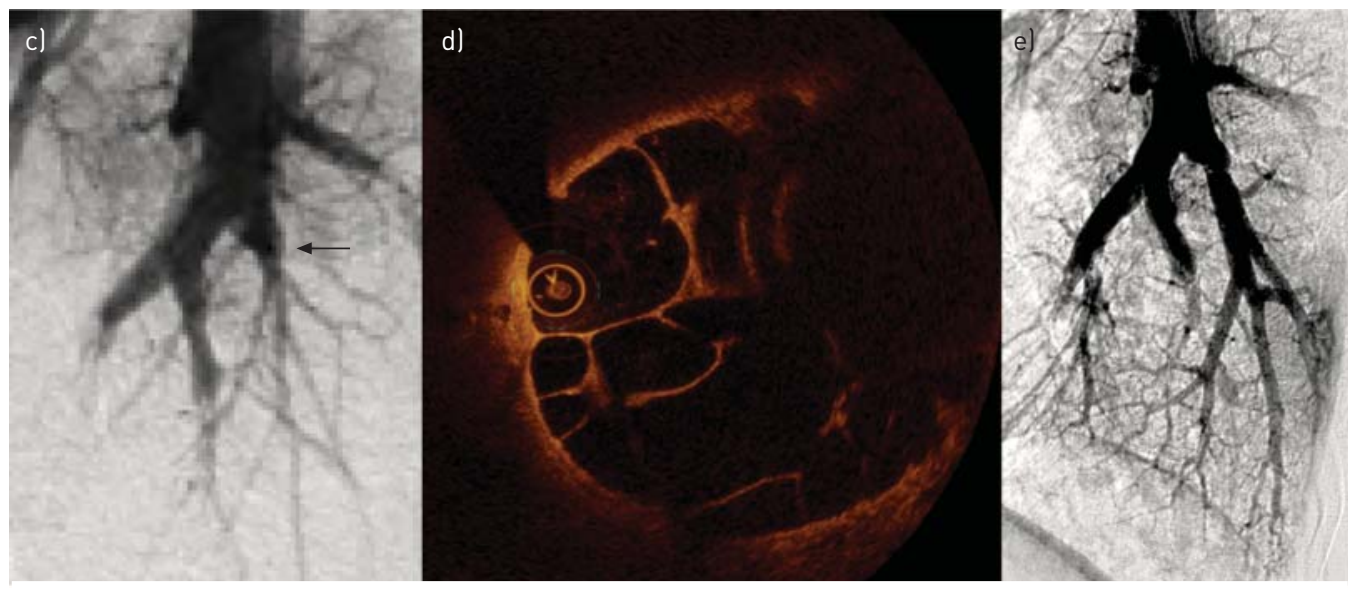

FIGURE 1 a) Segmentation of pulmonary arteries according to Cabrol. b) Table summarising the inflation pressure and size of balloons used for each treated segment. d) Visualisation of webs and splits with optical coherence tomography (OCT) before percutaneous angioplasty. Conventional pulmonary angiography of A8 segmental branch (left lung, lateral view) c) before and e) after balloon pulmonary angioplasty. Arrow indicates OCT cross section.

Multicentre studies are required to define indications, confirm efficacy and to establish long-term results. Pooling of skills of the interventional cardiologists, chest physicians specialised in pulmonary hypertension and representative surgical centres for PEA will allow optimisation of the technique and determine its place in the management of CTEPH patients $[9,10]$.

@ERSpublications

Balloon pulmonary angioplasty seems to be a feasible and efficient technique for the treatment of CTEPH http://ow.ly/u6MXl

Hélène Bouvaist ${ }^{1,2}$, Frédéric Thony ${ }^{2,3}$, Marie Jondot ${ }^{2,4}$, Boubou Camara ${ }^{2,4}$, Xavier Jais ${ }^{5,6,7}$ and Christophe Pison ${ }^{2,4,8,9}$ ${ }^{1}$ Clinique Universitaire de Cardiologie, Pôle Thorax, CHU Grenoble, Grenoble, France. ${ }^{2}$ Université Joseph Fourier, Grenoble, France. ${ }^{3}$ Clinique de Radiologie et Imagerie Médicale, Pôle Imagerie, CHU Grenoble, Grenoble, France. ${ }^{4}$ Clinique Universitaire de Pneumologie, Pôle Thorax, CHU Grenoble, Grenoble, France. ${ }^{5}$ Université Paris-Sud, Le Kremlin-Bicêtre, France. ${ }^{6}$ AP-HP, Service de Pneumologie, DHU Thorax Innovation, Hôpital Bicêtre, Le KremlinBicêtre, France. ${ }^{7}$ Inserm999, LabEx LERMIT, Centre Chirurgical Marie Lannelongue, Le Plessis Robinson, France. ${ }^{8}$ Inserm1055, Saint Martin d'Hères, France. ${ }^{9}$ European Institute for Systems Biology and Medicine, EISBM, Lyon, France.

Correspondence: Hélène Bouvaist, Clinique Universitaire de Cardiologie, CHU Grenoble, CS10217, 38043, Grenoble Cedex 9, France. E-mail: hbouvaist@chu-grenoble.fr

Received: Jan 182014 | Accepted after revision: Feb 132014

Support statement: This study was supported by a grant from CHU Grenoble (grant AO 2013DRC1324). 
Provenance: Submitted article, peer reviewed.

\section{References}

1 Jais X, D'Armini AM, Jansa P, et al. Bosentan for treatment of inoperable chronic thromboembolic pulmonary hypertension: BENEFiT (Bosentan Effects in iNopErable Forms of chronIc Thromboembolic pulmonary hypertension), a randomized, placebo-controlled trial. J Am Coll Cardiol 2008; 52: 2127-2134.

2 Pepke-Zaba J, Jansa P, Kim NH, et al. Chronic thromboembolic pulmonary hypertension: role of medical therapy. Eur Respir J 2013; 41: 985-990.

3 Kim NH, Delcroix M, Jenkins DP, et al. Chronic thromboembolic pulmonary hypertension. J Am Coll Cardiol 2013; 62: Suppl., D92-D99.

4 Jenkins DP, Madani M, Mayer E, et al. Surgical treatment of chronic thromboembolic pulmonary hypertension. Eur Respir J 2013; 41: 735-742.

5 Mizoguchi H, Ogawa A, Munemasa M, et al. Refined balloon pulmonary angioplasty for inoperable patients with chronic thromboembolic pulmonary hypertension. Circ Cardiovasc Interv 2012; 5: 748-755.

6 Sugimura K, Fukumoto Y, Satoh K, et al. Percutaneous transluminal pulmonary angioplasty markedly improves pulmonary hemodynamics and long-term prognosis in patients with chronic thromboembolic pulmonary hypertension. Circ J 2012; 76: 485-488.

7 Andreassen AK, Ragnarsson A, Gude E, et al. Balloon pulmonary angioplasty in patients with inoperable chronic thromboembolic pulmonary hypertension. Heart 2013; 99: 1415-1420.

8 Inami T, Kataoka M, Shimura N, et al. Pulmonary edema predictive scoring index (PEPSI), a new index to predict risk of reperfusion pulmonary edema and improvement of hemodynamics in percutaneous transluminal pulmonary angioplasty. JACC Cardiovasc Interv 2013; 6: 725-736.

9 Jenkins D, Mayer E, Screaton N, et al. State-of-the-art chronic thromboembolic pulmonary hypertension diagnosis and management. Eur Respir Rev 2012; 21: 32-39.

10 Lang IM, Pesavento R, Bonderman D, et al. Risk factors and basic mechanisms of chronic thromboembolic pulmonary hypertension: a current understanding. Eur Respir J 2013; 41: 462-468.

Eur Respir Rev 2014; 23: 393-395 | DOI: 10.1183/09059180.00000514 | Copyright ()ERS 2014 ERR articles are open access and distributed under the terms of the Creative Commons Attribution Non-Commercial Licence 4.0. 